\title{
MODELING OF M2-TIDE IN THE WESTERN WATERS OF ACEH, INDONESIA
}

\author{
ICHSAN SETIAWAN ${ }^{1}$, YUDI HADITIAR ${ }^{1}$, MUHAMMAD IKHWAN ${ }^{1}$, ZAQYATUN NUFUS ${ }^{2}$, \\ MUHAMMAD SYUKRI ${ }^{3}$, NAZLI ISMAIL ${ }^{3}$ AND SYAMSUL RIZAL*1,2
}

${ }^{1}$ Graduate School of Mathematics and Applied Sciences, ${ }^{2}$ Department of Marine Sciences, Faculty of Marine and Fisheries, ${ }^{3}$ Department of Physics, Faculty of Mathematics and Natural Sciences, Universitas Syiah Kuala, Banda Aceh 23111, Indonesia.

*Corresponding author: syamsul.rizal@unsyiah.net

Submitted final draft: 10 May $2020 \quad$ Accepted: 11 May 2020

http://doi.org/10.46754/jssm.2020.12.011

\begin{abstract}
The finite-difference 2D numerical model simulation was used to study the characteristics of currents, elevation, amplitude, and phase of M2-tide in the Western Waters of Aceh (WWA), Indonesia. The results show that the M2-tidal amplitude in WWA is between $14 \mathrm{~cm}$ and $17 \mathrm{~cm}$. The lowest value is in the middle of the WWA, while the highest value is in the northwest (NW). In the southeast (SE), the amplitude is $15 \mathrm{~cm}$. Phase values are in the range of 0 - 40 degrees. Contour lines indicate that M2-tidal waves move from SE to NW of WWA. Current ellipses show an anticlockwise rotation. The residual currents obtained from current ellipses move from SE to NW, and this is in line with the movement of the M2-tidal wave. Based on the M2-tidal amplitude, it was concluded that the M2-tidal wave had a weak impact on tidal currents at WWA. Semi-major amplitudes of current ellipses show relatively higher value in the western part of WWA compared to the eastern part of WWA. Also, residual currents are considerably strong in the shallows near the WWA coastline.
\end{abstract}

Keywords: Amplitude, phase, current ellipse, residual current.

\section{Introduction}

Today the global tides can be derived from tidal inversion software or online sites (Egbert \& Erofeeva, 2002; Price et al., 2018). The global tides can be used to describe the tides in large scale systems such as the Indian Ocean or the Bay of Bengal. However, in local or regional sites, the observation (Mayer-Gürr et al., 2012) or ocean modeling of tides are still needed (Pelling et al., 2013; Kumar \& Balaji, 2015; Othmani et al., 2017; Tazkia et al., 2017; Pringle et al., 2018; Deng et al., 2019). Mayer-Gürr et al. (2012) have combined the satellite altimetry and Gravity Recovery and Climate Experiment (GRACE) observation to improve a new tidal constituent model. They found that their method can improve the tidal prediction in a few areas above $60^{\circ} \mathrm{N}$. On the other hand, by using ocean modeling methods, Pelling et al. (2013) studied the impact of sea-level rise on the European Shelf tides. According to them, there is a response of tide due to sea-level increase. They concluded that sea-level rise shifts the tidal energy dissipation and makes the amphidromic points in the European Shelf toward the coastal. In regional sites, Kumar \& Balaji (2015) have studied the tides on the gulf of the west coast of India using the 2D numerical model with the spatially varied friction coefficient. They found that M2 and K1 tides are dominant compared to other constituents. Also, Othmani et al. (2017) have used the high-resolution 2D numerical model to study the tidal process and tidal characteristic on the Gulf of Gabes, Tunisia. They observed that the semidiurnal tides (M2 and S2) could generate significant sea-level variations and currents on the coast.

WWA is the coastal waters bordered by Sumatra Island and the Indian Ocean $\left(95.6^{\circ}\right.$ $96.3^{\circ} \mathrm{E}$ and $\left.4.0^{\circ}-4.65^{\circ} \mathrm{N}\right)$. These waters had a severe tsunami impact in December 2004. The tsunami had taken many lives and destroyed WWA infrastructures and the environment. The information on sea level tide is important to mitigate that disaster, and it can be used for coastal management and protection, especially in facing the sea level rise phenomenon (Daly et al., 2017). Also, tidal information can be 
used to study the distribution of pollutant or suspended sediment. According to Ramaswamy et al. (2007), the strong tidal currents, shallow depth, and presence of fine-grained sediments on the bottom floor are the primary factors for the high suspended sediment in the coastal area for example in the Gulf of Kachchh, India.

However, the tidal information in WWA is still limited. So far, the tides in WWA are known from the large or regional scale such as the Bay of Bengal (Sindhu and Unnikrishnan, 2013), the Andaman Sea, the Malacca Strait (Rizal et al., 2012), and Aceh Waters (Irham et al., 2018). The semidiurnal tides from the Indian Ocean propagate to the Andaman Sea, Malacca Strait, and also coastal waters in Sumatra, such as WWA.

In this study, we describe the hydrodynamics of M2-tide in WWA by using a high-resolution of a 2D numerical model. The tidal hydrodynamics in WWA is represented by the amplitudes, phases, residual currents, and ellipses of M2-tide. The importance of this research is to provide information on the M2tide of the location that can be used for fishery activities, shipping, tourism development, ports management, and other activities.

\section{Materials and Methods}

\section{Hydrodynamic Equation}

Ocean modeling which uses the Navier Stokes equation has been developed rapidly, see for e.g. Kämpf (2009; 2010), Mayer et al. (2010), Othmani et al. (2017), and Zhang et al. (2018). In this investigation, we use a 2D hydrodynamical model (Kämpf, 2009). The equations of motion are as follows:

$$
\begin{aligned}
& \frac{\partial u}{\partial t}+A d v_{h}(u)-f v=-g \frac{\partial \zeta}{\partial x}-\frac{i_{x}^{b o t}}{\rho_{0} h}+\operatorname{Diff}_{h}(u) \\
& \frac{\partial v}{\partial t}+A d v_{h}(v)+f u=-g \frac{\partial \zeta}{\partial y}-\frac{i_{y}^{b o t}}{\rho_{0} h}+\operatorname{Diff}_{h}(v),
\end{aligned}
$$

where,

$$
\begin{gathered}
A d v_{h(\mu)}, A d v_{h(v)} \quad \begin{array}{l}
\text { Advection in component } u \\
\text { and } v, \text { respectively }
\end{array} \\
\operatorname{Diff}_{h}(\mu), \operatorname{Diff}_{h}(v): \text { Diffusion in component } u \text { and } \\
v, \text { respectively }
\end{gathered}
$$

$$
\begin{aligned}
& f \quad \text { : Coriolis parameter } \\
& g \text { : Acceleration of gravity } \\
& h \quad: \text { Seawater depth (undisturbed sea level) } \\
& i_{x}^{b o t}, i_{y}^{b o t} \text { : Bottom stress in } x \text { and } y \text { direction, } \\
& \text { respectively } \\
& \rho_{0} \quad \text { : Reference density of seawater } \\
& t \quad \text { : time } \\
& \mu, v \quad \text { : Zonal velocity and meridional velocity } \\
& \xi \quad \text { : Sea level of M2-tide } \\
& x, y \quad \text { : Cartesian coordinates }
\end{aligned}
$$

We define the following variables as follows:

$$
\begin{gathered}
\operatorname{Diff}_{h}(u)=\frac{A h}{h}\left\{\frac{\partial}{\partial x}\left(h \frac{\partial u}{\partial x}\right)+\frac{\partial}{\partial y}\left(h \frac{\partial u}{\partial y}\right)\right\} \\
\operatorname{Diff}_{h}(v)=\frac{A h}{h}\left\{\frac{\partial}{\partial x}\left(h \frac{\partial v}{\partial x}\right)+\frac{\partial}{\partial y}\left(h \frac{\partial v}{\partial y}\right)\right\} \\
A d v_{h}(u)=u \frac{\partial u}{\partial x}+v \frac{\partial u}{\partial y}=\frac{\partial(u u)}{\partial x}+\frac{\partial(u v)}{\partial y}-u\left(\frac{\partial u}{\partial x}+\frac{\partial v}{\partial y}\right)(5) \\
A d v_{h}(v)=u \frac{\partial v}{\partial x}+v \frac{\partial v}{\partial y}=\frac{\partial(u v)}{\partial x}+\frac{\partial(v v)}{\partial y}-v\left(\frac{\partial u}{\partial x}+\frac{\partial v}{\partial y}\right)(6) \\
\bar{\imath}_{x}^{b o t}=\rho_{0} r u \sqrt{u^{2}+v^{2}} \\
i_{y}^{b o t}=\rho_{0} r v \sqrt{u^{2}+v^{2}},
\end{gathered}
$$

where,

$A_{h} \quad$ : Horizontal eddy coefficient

$r$ : non-dimensional bottom friction coefficient

For the stability, the model respects the CourantFriedrichs-Lewy (CFL) criterion for the twodimensional equations:

$$
\Delta t \leq \frac{\min (\Delta x, \Delta y)}{\sqrt{2 g h_{\max }}},
$$

where,

$\Delta t \quad$ : Time step

$\Delta x, \Delta y:$ Distance spacing in longitude and latitude, respectively

$h_{\max }:$ Maximum depth of water or an undisturbed sea level

At the open boundaries, the amplitudes and phases are prescribed and we use the following equation:

$$
\xi(t)=A \cos (t-\varphi),
$$

where,

A : Tidal amplitude

$\omega \quad$ : Tidal angular velocity,

$T \quad$ : M2-tidal period 
$\varphi \quad$ : Tidal phase

Where $\xi(t)$ is the height of the M2-tide as time $t, A$ is the amplitude of M2-tidal component, is the phase of M2-tide.

$$
\begin{gathered}
\zeta_{j, 0}^{n}=\zeta_{j, 1}^{n} \\
\zeta_{j, n x+1}^{n}=\zeta_{j, n x}^{n} \\
\zeta_{0, k}^{n}=\zeta_{1, k}^{n} \\
\zeta_{n y+1, k}^{n}=\zeta_{n y, k}^{n},
\end{gathered}
$$

where Eq. (11), Eq. (12), Eq. (13), and Eq. (14) are the open boundaries of M2-tide at the western, eastern, southern, and northern areas, respectively (with $j=1,2,3, \ldots, n y, k=1,2,3$, $\ldots, n x$, and $n$ is time index).

The amplitude and phase are calculated in the following way:

$\zeta_{x}$ and $\zeta_{y}$ are:

$$
\begin{gathered}
A=\sqrt{\left(\zeta_{x}^{2}+\zeta_{y}^{2}\right)} \\
\varphi=\tan ^{-1}\left(\frac{\zeta_{y}}{\zeta_{x}}\right)
\end{gathered}
$$

$$
\begin{gathered}
\zeta_{x}=0.5\left(\zeta^{T}-\zeta^{T / 2}\right) \\
\zeta_{y}=0.5\left(\zeta^{T / 4}-\zeta^{3 T / 4}\right),
\end{gathered}
$$

where $\xi^{T / 4}, \xi^{T / 2}, \xi^{3 T / 4}$, and $\xi^{T}$ are sea levels at time $t$ $=T / 4, T / 2,3 T / 4$, and $T$, respectively.

The validation of the M2-tide of the model consisting of amplitude and phase is compared with the Geospatial Information Agency, Indonesian data (GIA), and other sources.

\section{Research Methods}

This research was carried out with the following steps:

1) Prepare bathymetric input data from SRTM30 (ftp://topec.ucsd.edu/pub/srtm30 plus), M2-tidal amplitudes, and phases at the open boundary conditions (Geospatial Information Agency, Indonesian data). We used GIA data for open boundary conditians because GIA data have a high resolution (2.5 minutes) compared to TMD (7.5 minutes) and FES (7.5 minutes). GIA data is analyzed from the University of Hawaii Sea Level Center (UHSLC) data by Tropical Ocean Global Atmosphere (TOGA) software (details about GIA data can be seen on http://tides.big.go.id/). The data are available for Indonesia Waters and the adjacent seas.

2) Simulation with a two-dimensional numerical model used the equations of motion described above. The sensitivity of several the non-dimensional bottom friction coefficient $(r)$ values, i.e. $r=0.0001, r=$ $0.0025, r=0.005$, and $r$ based on depth values with $r=g /\left(62.64 \mathrm{~m}^{0.5} / \mathrm{s}\right)^{2}$, if $h \leq 40 \mathrm{~m}$; $r=g /\left(62.64 \mathrm{~m}^{0.5} / \mathrm{s}+(h-40 \mathrm{~m})^{0.5} / \mathrm{s}\right)^{2}$ if $40 \mathrm{~m}<$ $h \leq 65 \mathrm{~m}$, and $r=g /\left(87.64 \mathrm{~m}^{0.5} / \mathrm{s}\right)^{2}$, if $h>65$ m (Rizal \& Sündermann, 1994) was tested. To obtain numerical simulation stability, the simulation was performed during 40 iterations of the M2-tidal period ( $T=12.42$ hours). The analysis of results is derived from the last of the iteration, namely at time $t=T / 4, T / 2,3 T / 4$, and $T$. Then, we chose numerical simulations using $r$ of the best choice.

3) The resulting outputs are the M2-tide of currents, amplitudes, and phases.

4) The amplitude and phase are verified by using the analysis data from GIA, Tide Model Driver (TMD), and Finite Element Solution (FES). Then, the difference between the model results and other data (GIA, TMD, and FES) is quantified by the Root Mean Square Error (RMSE) defined as follows (Othmani et al., 2017):

$$
\text { RMSE }=\sqrt{\frac{1}{N} \sum_{i=1}^{N}\left|X_{m o d}-X_{d a t a}\right|^{2}},
$$

where $N$ defines the number of wet grid points used, $\boldsymbol{X}_{\text {mod }}$ defines the model data (M2-tidal amplitudes or M2-tidal phases), and $\boldsymbol{X}_{\text {data }}$ defines its verification from GIA, TMD, and FES. 


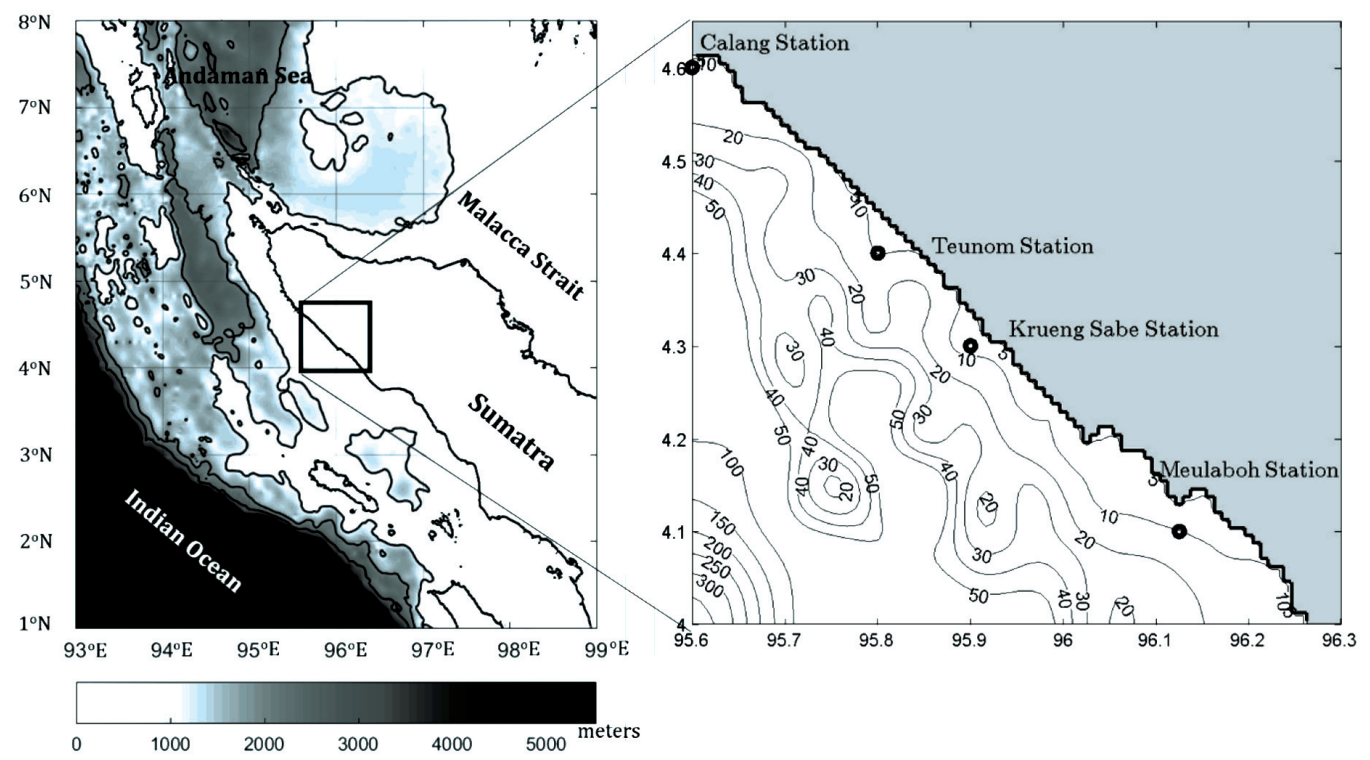

Figure 1: The bathymetry of Western Waters of Aceh, Indonesia, based on SRTM30 (depths are in meters)

This research was conducted with the discretization of $\Delta x=\Delta y=0.5$ minutes, the time step $\Delta t=10 \mathrm{~s}$, and $=500 \mathrm{~m}^{2} / \mathrm{s}$. Figure 1 shows the bathymetry of the WWA obtained from SRTM30.

\section{Results and Discussion}

The first results tested the sensitivity of several non-dimensional bottom friction coefficient $(r)$ values, i.e. $r=0.0001, r=0.0025, r=$ 0.005 , and $r$ based on depth values (Rizal and
Sündermann, 1994). The results obtained show that the different $r$ values do not show a striking difference in output for both amplitude (see Table 1) and phase (see Table 2).

Thus, we chose numerical simulations using $r$ based on depth. The next results discussed are tidal currents, M2-tidal amplitudes and phases, current ellipses and residual current of M2-tide by using based on depth (Rizal \& Sündermann, 1994).

Table 1: M2-tidal amplitude with the non-dimensional bottom friction coefficient $(r)$ variation of each station

\begin{tabular}{|c|c|c|c|c|c|c|c|}
\hline \multirow{3}{*}{ Station } & \multirow{3}{*}{$\begin{array}{l}\text { Latitude } \\
\left({ }^{\circ} \mathbf{N}\right)\end{array}$} & \multirow{3}{*}{$\begin{array}{l}\text { Longitude } \\
\left({ }^{\circ} \mathbf{E}\right)\end{array}$} & \multicolumn{5}{|c|}{ Amplitude (cm) } \\
\hline & & & \multicolumn{4}{|c|}{ Model } & \multirow[b]{2}{*}{ GIA } \\
\hline & & & $r=0.0001$ & $r=0.0025$ & $r=0.005$ & $\begin{array}{c}r \text { based on } \\
\text { depth }\end{array}$ & \\
\hline Calang & 4.6 & 95.6 & 16.90 & 16.92 & 16.94 & 16.92 & 17.33 \\
\hline Teunom & 4.4 & 95.8 & 15.37 & 15.37 & 15.37 & 15.38 & 14.58 \\
\hline Krueng Sabe & 4.3 & 95.9 & 14.77 & 14.82 & 14.87 & 14.82 & 13.85 \\
\hline Meulaboh & 4.1 & 96.2 & 15.21 & 15.23 & 15.25 & 15.23 & 14.74 \\
\hline Western of WWA & 4.3 & 95.65 & 14.45 & 14.45 & 14.45 & 14.45 & 14.60 \\
\hline $\begin{array}{c}\text { Northwest of } \\
\text { WWA }\end{array}$ & 4.05 & 95.65 & 13.95 & 13.96 & 13.96 & 13.95 & 13.89 \\
\hline Southern of WWA & 4.05 & 95.9 & 14.37 & 14.37 & 14.38 & 14.38 & 14.27 \\
\hline
\end{tabular}


Table 2: M2-tidal phase with the non-dimensional bottom friction coefficient $(r)$ variation of each station

\begin{tabular}{|c|c|c|c|c|c|c|c|}
\hline \multirow{3}{*}{ Station } & \multirow{3}{*}{$\begin{array}{l}\text { Latitude } \\
\left({ }^{\circ} \mathbf{N}\right)\end{array}$} & \multirow{3}{*}{$\begin{array}{l}\text { Longitude } \\
\left({ }^{\circ} \mathbf{E}\right)\end{array}$} & \multicolumn{5}{|c|}{ Phase $\left({ }^{\circ}\right)$} \\
\hline & & & \multicolumn{4}{|c|}{ Model } & \multirow[b]{2}{*}{ GIA } \\
\hline & & & $r=0.0001$ & $r=0.0025$ & $r=0.005$ & $\begin{array}{c}r \text { based on } \\
\text { depth }\end{array}$ & \\
\hline Calang & 4.6 & 95.6 & 43.71 & 43.52 & 43.40 & 43.52 & 42.95 \\
\hline Teunom & 4.4 & 95.8 & 22.94 & 22.63 & 22.39 & 22.64 & 27.76 \\
\hline Krueng Sabe & 4.3 & 95.9 & 13.88 & 13.78 & 13.68 & 13.79 & 18.98 \\
\hline Meulaboh & 4.1 & 96.2 & 0 & 0 & 0 & 0 & 0 \\
\hline Western of WWA & 4.3 & 95.65 & 24.30 & 24.29 & 24.29 & 24.28 & 25.6 \\
\hline $\begin{array}{l}\text { Northwest of } \\
\text { WWA }\end{array}$ & 4.05 & 95.65 & 6.27 & 6.27 & 6.26 & 6.27 & 6.85 \\
\hline $\begin{array}{l}\text { Southern of } \\
\text { WWA }\end{array}$ & 4.05 & 95.9 & 0 & 0 & 0 & 0 & 0 \\
\hline
\end{tabular}

\section{Tidal Current}

The pattern of tidal currents of the model simulation at the ebb tide $(t=T / 4)$ shows that the relatively strong current moves from the north to the south, along with the western open boundary. Along the coastline, the weak current moves from NW to SE (see Figure 2).

At the low tide $(t=T / 2)$, as shown in Figure 3 , the current generally move from NW to SE. Along the coastline, the current magnitude weakens. Close to the north-south open boundary, the speed is around $15 \mathrm{~cm} / \mathrm{s}$.
At flood tide $(t=3 T / 4)$, see Figure 4 , at the western part, currents move from south to north at speed of around $15 \mathrm{~cm} / \mathrm{s}$. Whereas, along the coastline, the weak current moves from SE to NW.

When high tide $(t=T)$, see Figure 5, the current direction is dominated by flow moving from SE to NW with a minimum speed of $5 \mathrm{~cm} / \mathrm{s}$ and a maximum speed of $15 \mathrm{~cm} / \mathrm{s}$. Still, along the coastline, the weak current flow from SE to NW.

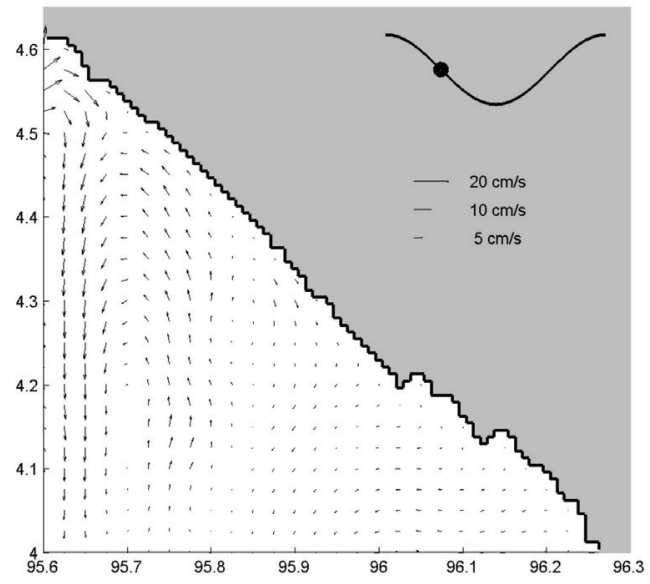

Figure 2: Current circulation during ebb tide (at $t=T / 4$ ) 


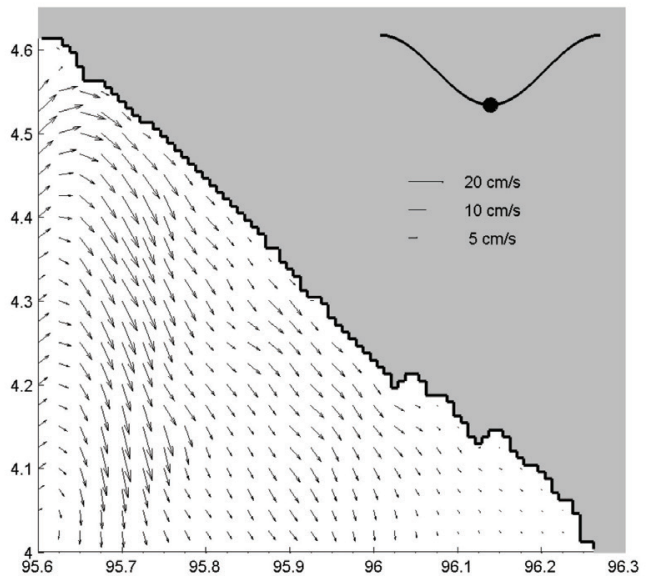

Figure 3: Current circulation during low tide (at $t=T / 2$ )

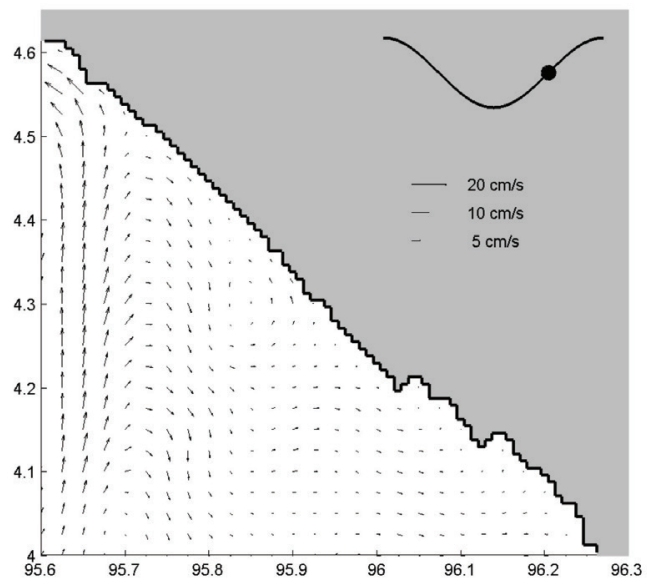

Figure 4: Current circulation during flood tide (at $t=3 T / 4$ )

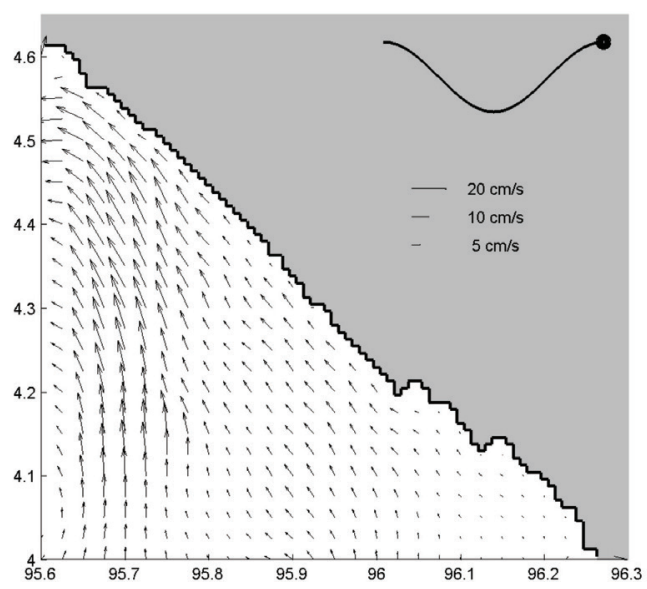

Figure 5: Current circulation during high tide (at $t=T$ ) 


\section{M2-tidal Amplitudes and Phases}

The amplitude pattern of M2-tide is shown in Figure 6. M2-tidal amplitude values range from $14 \mathrm{~cm}$ to $17 \mathrm{~cm}$. The lowest amplitude value of $14 \mathrm{~cm}$ is found in $\mathrm{SE}$ and continues to increase until the highest value of $17 \mathrm{~cm}$ in NW. Figure 7 shows the M2-tidal contour amplitudes based on GIA data. Figures 8 and 9 show the M2-tidal amplitude contours obtained from TMD and FES data.

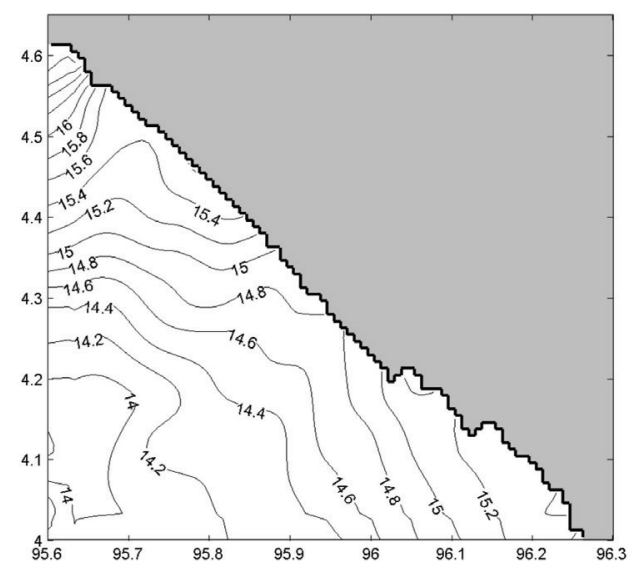

Figure 6: The M2-tidal amplitude of model (cm)

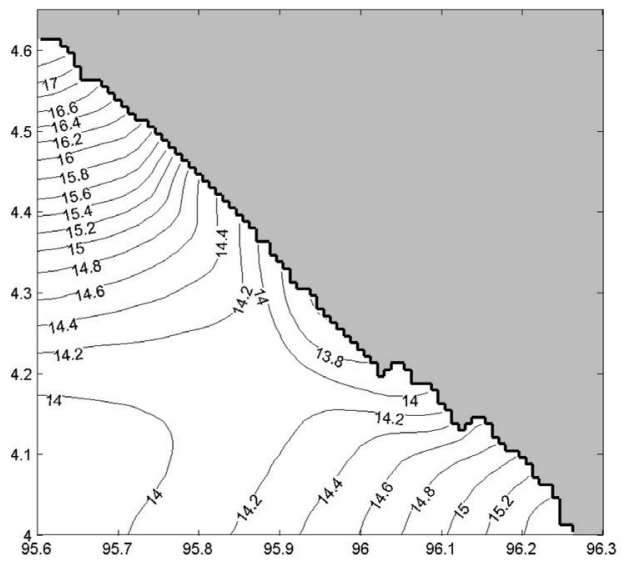

Figure 7: The M2-tidal amplitude of GIA data, Indonesian (cm) 


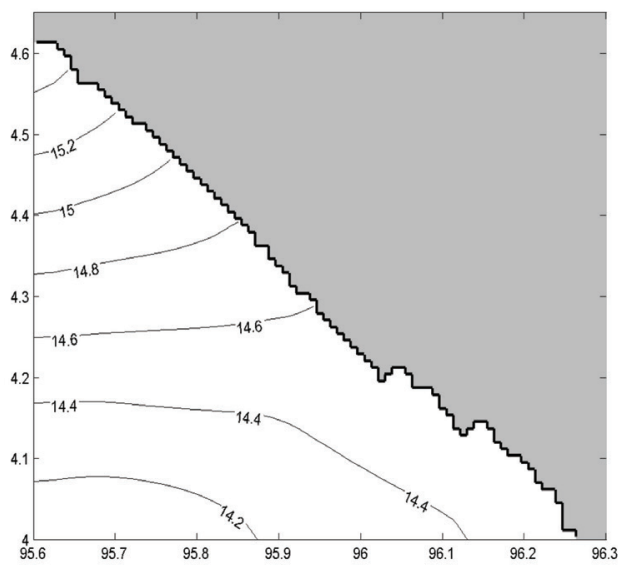

Figure 8: The M2-tidal amplitude of TMD data $(\mathrm{cm})$

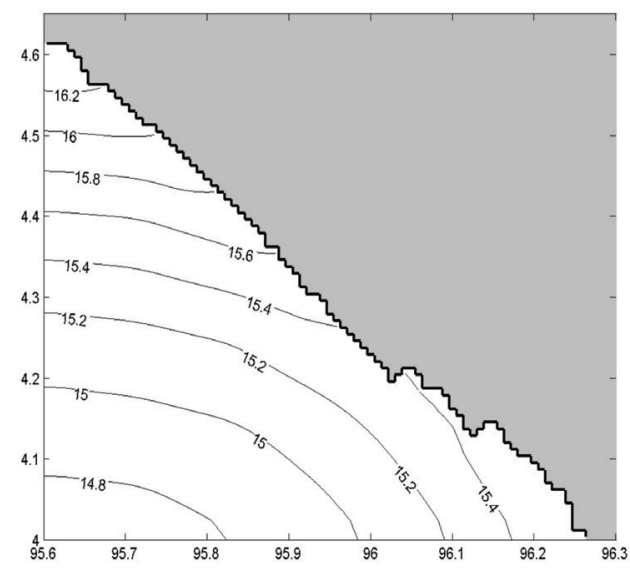

Figure 9: The M2-tidal amplitude of FES data $(\mathrm{cm})$

Meanwhile, phase of M2-tide is shown in Figure 10. The values of the phase contour lines are about $0^{\circ}-40^{\circ}$. The phase value starts from $0^{\circ}$ in SE and increases towards the value of $40^{\circ}$ in NW. Figure 11 shows the phase based on GIA data. Figures 12 and 13 show the M2-tidal phase obtained from TMD and FES data, respectively. 


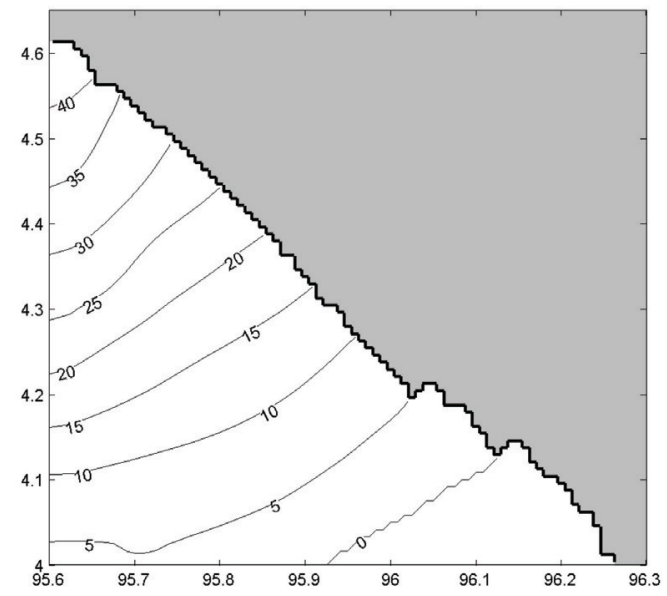

Figure 10: The M2-tidal phase of the model (degrees in GMT)

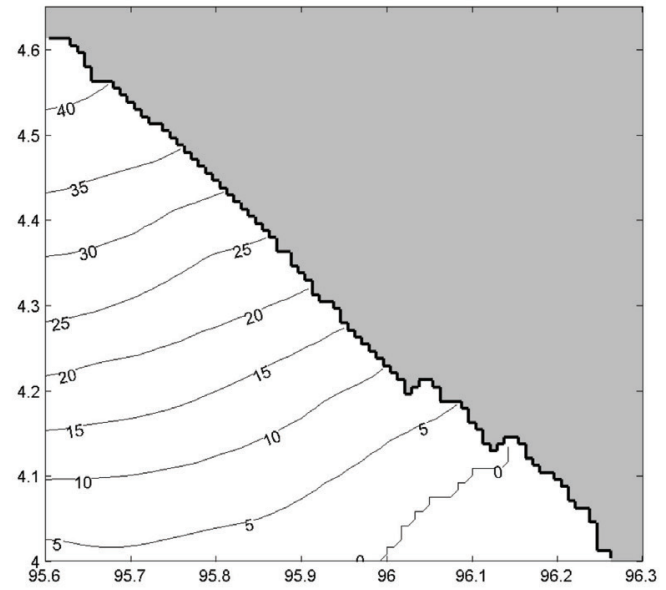

Figure 11: The M2-tidal phase of the GIA data (degrees in GMT)

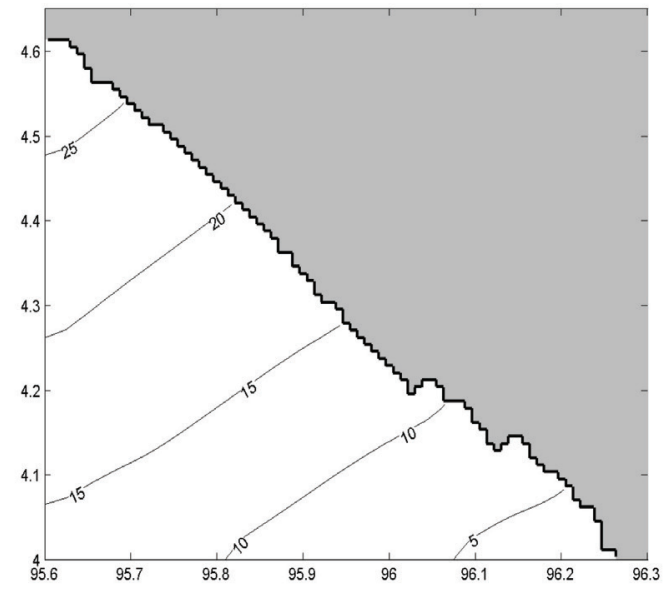

Figure 12: The M2-tidal phase of the TMD data (degrees in GMT) 


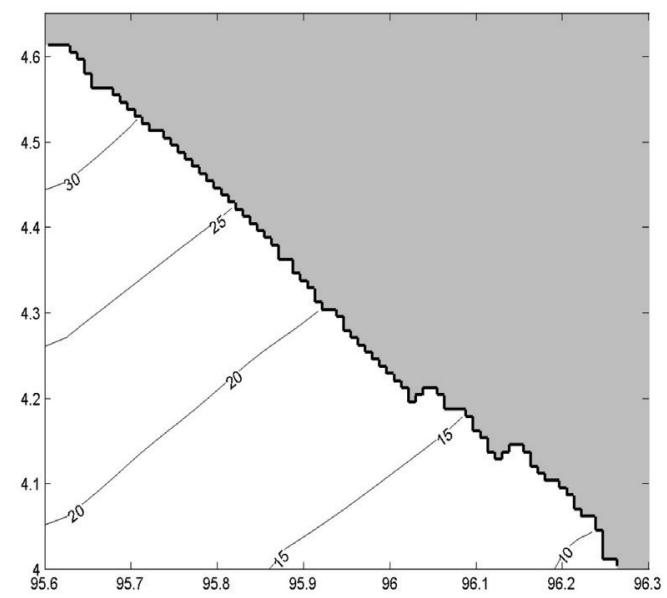

Figure 13: The M2-tidal phase of the FES data (degrees in GMT)

Tables 3 and 4 show the verification of four stations, i.e., Calang, Teunom, Krueng the M2-tide between the model, GIA, TMD, Sabe, and Meulaboh. The station locations are and FES data, in terms of amplitudes (cm) and shown in Figure 1. phases (degrees in GMT), respectively. We use

Table 3: M2-tidal amplitude of each station

\begin{tabular}{ccccccc}
\hline \multirow{2}{*}{ Station } & $\begin{array}{c}\text { Latitude } \\
\left({ }^{\circ} \mathbf{N}\right)\end{array}$ & $\begin{array}{c}\text { Longitude } \\
\left({ }^{\circ} \mathbf{E}\right)\end{array}$ & Model & GIA & TMD & FES \\
\cline { 4 - 7 } & 4.6 & 95.6 & 17 & 17 & 16 & 16 \\
Calang & 4.4 & 95.8 & 16 & 15 & 15 & 16 \\
Teunom & 4.3 & 95.9 & 15 & 14 & 15 & 15 \\
Krueng Sabe & 4.1 & 96.2 & 15 & 15 & 14 & 15 \\
Meulaboh & & & & & & \\
\hline
\end{tabular}

Table 4: M2-tidal phase of each station

\begin{tabular}{|c|c|c|c|c|c|c|}
\hline \multirow{2}{*}{ Station } & \multirow{2}{*}{$\begin{array}{c}\text { Latitude } \\
\left({ }^{\circ} \mathbf{N}\right)\end{array}$} & \multirow{2}{*}{$\begin{array}{c}\text { Longitude } \\
\left({ }^{\circ} \mathbf{E}\right)\end{array}$} & \multicolumn{4}{|c|}{ Phase $\left(^{\circ}\right)$} \\
\hline & & & Model & GIA & TMD & FES \\
\hline Calang & 4.6 & 95.6 & 44 & 43 & 28 & 34 \\
\hline Teunom & 4.4 & 95.8 & 23 & 28 & 20 & 25 \\
\hline Krueng Sabe & 4.3 & 95.9 & 14 & 19 & 16 & 20 \\
\hline Meulaboh & 4.1 & 96.2 & 0 & 0 & 7 & 13 \\
\hline
\end{tabular}


The M2-tidal amplitude values obtained from the model show that these values range from $14 \mathrm{~cm}$ to $17 \mathrm{~cm}$. From this lowest value, the amplitude increases from $14 \mathrm{~cm}$ to $17 \mathrm{~cm}$ to NW section and $15.4 \mathrm{~cm}$ to SE section. A similar pattern occurs in M2-tidal amplitude of the GIA, TMD, and FES data.

The model phases are similar to that of GIA, TMD, and FES, directed from SE to NW of WWA. The phase of the model is from $0^{\circ}$ to $40^{\circ}$. Meanwhile, the phases of GIA, TMD, and FES are $0^{\circ}$ to $40^{\circ}, 5^{\circ}$ to $25^{\circ}$, and $10^{\circ}$ to $30^{\circ}$, respectively.

If we compare the phase of the model to other studies (Rizal et al., 2012; Shindu \& Unnikrishnan, 2013), the phases of the model show compelling results. The increase of M2tidal amplitude and phase in WWA are caused by the M2-tidal wave that was directed from the tropical eastern of the Indian Ocean to the west of Aceh Waters. According to Sindhu et al. (2013), the change of M2-tidal amplitude between that point is relatively small $(10-20 \mathrm{~cm})$ compared to the Andaman Sea and the Malacca Strait. Furthermore, if we compared WWA and the Eastern Waters of Aceh (EEA) connecting to the Malacca Strait, the M2-tidal waves have a weak effect on the tidal circulation. Also, it can be seen in Table 3, amplitudes comparison between the model results and GIA, TMD, and FES shows they agree very well at four stations. The same results are shown in Table 4. The phases obtained from the model are almost similar to those of GIA, TMD, and FES data.

RMSE is used to verify our results (Figures 6 and 10) with the other data, namely GIA (Figures 7 and 11), TMD (Figures 8 and 12), and FES (Figures 9 and 13). RMSE of M2-tidal amplitude between the model result and GIA is $0.4368 \mathrm{~cm}$, while for the model result and TMD is $0.3952 \mathrm{~cm}$, and for the model result and FES is $0.6010 \mathrm{~cm}$. Results showed that most RMSE of M2-tidal amplitudes is below $0.6 \mathrm{~cm}$. Meanwhile, the RMSE of M2-tidal phases is $2.4439^{\circ}, 5.9734^{\circ}, 9.1073^{\circ}$, respectively. It means that the model results for M2-tidal amplitudes and phases show a good agreement with the verification (GIA, TMD, and FES). Therefore, we can use our model for further analysis.

At $t=T / 2$ and $T$, the current magnitude reaches $15 \mathrm{~cm} / \mathrm{s}$. The current velocity when $t$ $=T / 2$ and $T$ has the same magnitude, but they have opposite directions. At $t=T / 2$, the current moves from NW to SE, and when $t=T$, the current moves from SE to NW. Moreover, when $t=T / 4$ and $3 T / 4$, their current magnitudes have relatively the same speed, but they have the opposite direction. The speed reaches $15 \mathrm{~cm} / \mathrm{s}$ near the western open boundary. In the west when $t=T / 4$, the current moves from the north to the south and when $t=3 T / 4$ the current moves from the south to the north. During all periods of M2-tide, the M2-tidal current is always strong because the M2-tidal amplitude gradient is high at the western part of WWA compared to the southern part of WWA.

\section{Current Ellipses and Residual Current of M2- tide}

Figure 14 shows the M2-tidal currents for one period. This current pattern is in the form of an ellipse. All ellipses formed have anticlockwise orientations with the semi-major amplitude (or maximal velocity in one period of M2-tide) values ranging from $5-15 \mathrm{~cm} / \mathrm{s}$.

We also calculate the residual currents with the following equation (Rizal \& Sündermann, 1994):

where,

$$
v_{r e s}=\frac{\int_{0}^{T} v H d t}{\int_{0}^{T} H d t}
$$

$$
\begin{array}{ll}
v_{r e s} & : \text { Residual current of component and } \\
\boldsymbol{v} & : \text { Resultant of component and } \\
H & : h+\xi
\end{array}
$$

The result of the M2-tidal residual current is shown in Figure 15. The current pattern indicates that the current moves from SE to NW with speeds between $0.05 \mathrm{~cm} / \mathrm{s}$ to $0.1 \mathrm{~cm} / \mathrm{s}$. This residual current movement is in line with the increase of the M2-tidal phase shown in Figures 10-13. 


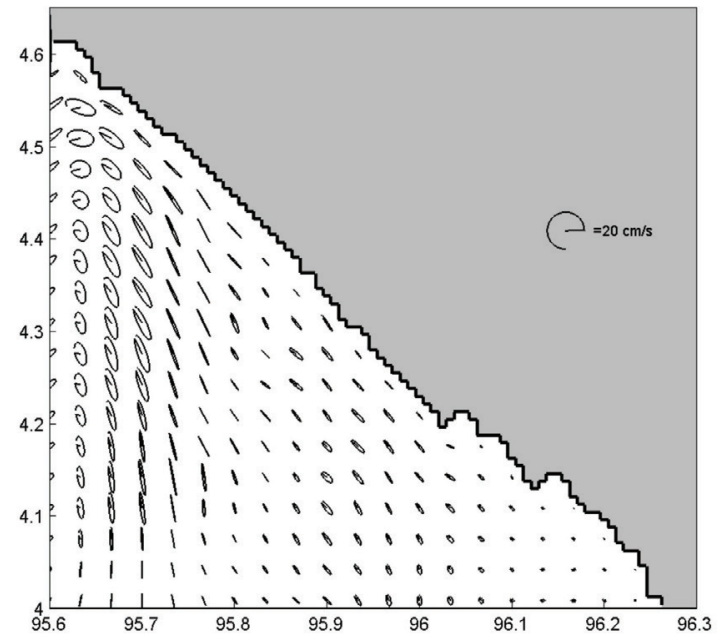

Figure 14. Current ellipses of M2-tide $(\mathrm{cm} / \mathrm{s})$ based on the model

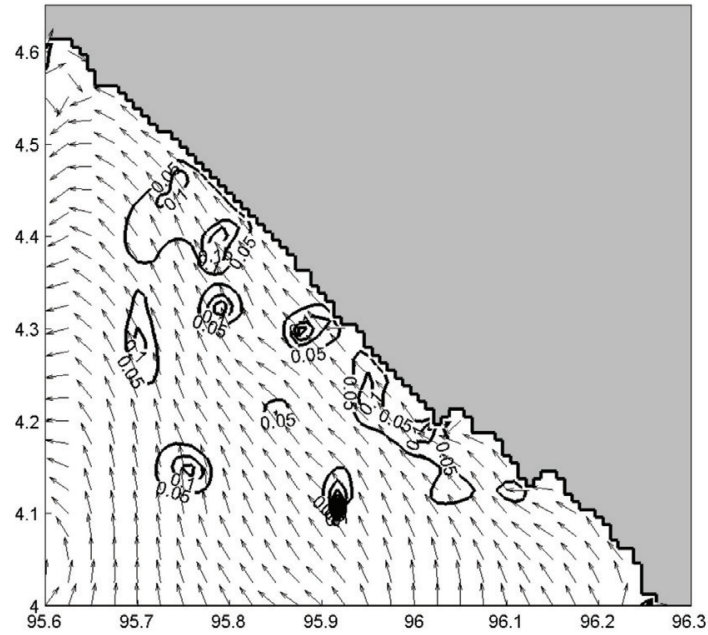

Figure 15. Residual current of M2-tide $(\mathrm{cm} / \mathrm{s})$ based on model

The values of semi-major amplitudes of current ellipses have larger values in the western part than those in the eastern part of WWA. The high value of the semi-major amplitude is around $12 \mathrm{~cm} / \mathrm{s}$ at the point $4.53{ }^{\circ} \mathrm{N}, 95.63{ }^{\circ} \mathrm{E}$.

The results of the residual current calculation show that the direction of the currents flows from SE to NW of WWA. The largest residual current is around $0.1 \mathrm{~cm} / \mathrm{s}$, and the smallest one is smaller than $0.05 \mathrm{~cm} / \mathrm{s}$. The residual current is active in the shallow region and close to the WWA coastline. The direction of the residual current is in line with the increase in the phase value of M2-tide.

\section{Conclusion}

The modeling of M2-tide has been carried out in WWA. At $t=T$, the current moves from SE to NW, whereas when $t=T / 2$, the current moves from NW to SE. The M2-tidal amplitude and M2-tidal phase values obtained from the model results are in accordance with GIA, TMD, and FES data. Based on the amplitude results, the M2-tidal waves have a weak effect on the tidal circulation in WWA. 
Current ellipses of M2-tide move counterclockwise with semi-major amplitude value reaching $12 \mathrm{~cm} / \mathrm{s}$ in NW and the western parts of WWA. While in SE part, the semi-major is only about $5 \mathrm{~cm} / \mathrm{s}$. The semi-major amplitudes of current ellipses have significant values in the western part of WWA compared to the eastern part of WWA. The residual current of M2-tide moves from SE to NW, and this confirms the findings of the increasing phases of M2-tide from SE to NW. The residual current is strong in the shallow region, which is closest to the WWA coastline.

This tidal study can be used as a study for marine protected areas, for port development, tourism, navigation, shipping and fishing activities. Based on this M2-tidal modeling, further research is recommended to do be carried out which are related to the distribution of sediment and the spread of pollutants from industrial and mining activities. In addition, with external forces in the form of tides and winds, a study of the flow of marine debris from domestic waste and nutrient distribution from estuaries can be carried out.

\section{Acknowledgements}

The authors would like to express gratitude to the Ministry of Research, Technology, and Higher Education of Indonesia through 'Penelitian Dasar', with contract number: 72/UN11.2/PP/ SP3/2019. The authors would like to thank the respondents of the study, whose participation and cooperation had made this this study and manuscript possible.

\section{References}

Daly, P., Halim A., Nizamuddin, Ardiansyah, Hundlani D., ... Mahdi, S. (2017). Rehabilitating coastal agriculture and aquaculture after inundation events: Spatial analysis of livelihood recovery in posttsunami Aceh, Indonesia. Ocean \& Coastal Management, 142, 218-232. https://doi. org/10.1016/j.ocecoaman.2017.03.027
Deng, F., Jiang, W., Valle-Levinson, A., \& Feng, S. (2019). 3D Modal Solution for Tidally Induced Lagrangian Residual Velocity with Variations in Eddy Viscosity and Bathymetry in a Narrow Model Bay. Journal of Ocean University of China, 18(1), 69-79. https://doi.org/10.1007/s11802-019-3773-1

Egbert, G. D., \& Erofeeva, S. Y. (2002). Efficient inverse modeling of barotropic ocean tides. Journal of Atmospheric and Oceanic Technology, 19(2), 183-204. https://doi. org/10.1175/1520-0426(2002)019\%3C0

183 : E I M O B O \% 3 E 2 . 0 . C O ; 2

Irham, M., Miswar, E., Ilhamsyah, Y., \& Setiawan, I. (2018). The northern tidal dynamic of Aceh waters: A 3D numerical model. IOP Conf. Ser: Mater. Sci. Eng, 352 012043. https://doi. org/10.1088/1757-899X/352/1/012043

Kämpf, J. (2009). Ocean modelling for beginner. usingopen-sourcesoftware. Springer Verlag,

Kämpf, J. (2010). Advanced ocean modelling using open-source software. Heidelberg: Springer Verlag.

Kumar, S. S., \& Balaji, R. (2015). Tidal Hydrodynamics along Gulf of Khambhat, West Coast of India. Journal of Aquatic Procedia, 4, 41-48. https:// doi.org/10.1016/j.aqpro.2015.02.007

Mayer, B., Damm P. E., Pohlmann, T., \& Rizal, S. (2010). What is driving the ITF? An illumination of the Indonesian throughflow with a numerical nested model system. Dynamics of Atmospheres and Oceans, 50, 301-312. https://doi. org/10.1016/j.dynatmoce.2010.03.002

Mayer-Gürr, T., Savcenko, R., Bosch, W., Daras, I., Flechtner, F., \& Dahle, C. (2012). Ocean tides from satellite altimetry and GRACE. Journal of Geodynamics, 59-60, 28-38. https://doi.org/10.1016/j.jog.2011.10.009

Othmani, A., Bejaou, B., Chevalier, C., Elhmaidi, D., Devenon, J. L., \& Aleya, L. (2017). High resolution numeric modelling of the barotropic tides in the 
Gulf of Gabes, eastern Mediterranean Sea (Tunisia). Journal of African Earth Sciences, 129, 224-232. https://doi. org/10.1016/j.jafrearsci.2017.01.007

Pelling, H. E., Mattias Green, J. A., \& Ward, S. L. (2013). Modelling tides and sealevel rise: To flood or not to flood. Ocean Modelling, 63, 21-29. https:// doi.org/10.1016/j.ocemod.2012.12.004

Price, C., Maor, R., \& Shachaf, H. (2018). Using smartphones for monitoring atmospheric tides. Journal of Atmospheric and Solar-Terrestrial Physics, 174, 1-4. https://doi.org/10.1016/j.jastp.2018.04.015

Pringle, W. J., Wirasaet, D., Suhardjo, A., Meixner, J., Westerink, J. J., ... Nong S. (2018). Finite-element barotropic model for the Indian and Western Pacific Oceans: Tidal model-data comparisons and sensitivities. Ocean Modelling, 129, 13-38. https:// doi.org/10.1016/j.ocemod.2018.07.003

Ramaswamy, V., Nath, B. N., Vethamony, P., \& Illangovan, D. (2007). Source and dispersal of suspended sediment in the macro-tidal Gulf of Kachchh. Marine Pollution Bulletin, 54(6), 708-719. https:// doi.org/10.1016/j.marpolbul.2007.01.026

Rizal, S., Damm, P., Wahid, M. A., Sündermann, J., Ilhamsyah, Y., ... Muhammad. (2012).
General circulation in the Malacca Strait and Andaman Sea: A numerical model study. American Journal of Environmental Sciences, 8(5), 479-488. https://doi. org/10.3844/ajessp.2012.479.488

Rizal, S., \& Sündermann, J. (1994). On the M2-tide of the Malacca Strait: A numerical investigation. Deutsche hydrographische Zeitschrift, 46(1), 61-80. https://doi.org/10.1007/BF02225741

Sindhu, B., \& Unnikrishnan, A. S. (2013). Characteristics of tides in the Bay of Bengal. Marine Geodesy, 36, 377-407. https://doi.or $\mathrm{g} / 10.1080 / 01490419.2013 .781088$

Tazkia, A. R., Krien, Y., Durand, F., Testut, L., Islam, A. S., ... Bertin, X. (2017). Seasonal modulation of M2 tide in the Northern Bay of Bengal. Continental Shelf Research, 137, 154-162. https:// doi.org/10.1016/j.csr.2016.12.008

Zhang, J., Liang, D., \& Liu, H. (2018). A hybrid hydrostatic and non-hydrostatic numerical model for shallow flow simulations. Estuarine, Coastal and Shelf Science, 205, 21-29. https:// doi.org/10.1016/j.ecss.2018.03.012 